\section{Espacio y dinámicas subversivas en Madeinusa}

Space and subversive dynamics in Madeinusa

Ignacio D. Arellano-Torres iarellanotorres@gmail.com

Stony Brook University, EE.UU.

FECHA DE RECEPCIÓN mayo 27,2019

FECHA DE APROBACIÓN agosto 13, 2019

FECHA DE PUBLICACIÓN enero 1, 2020

https://doi.org/10.32870/ elojoquepiensa.v0i20.328
RESUMEN / El presente trabajo propone una lectura de la película Madeinusa (2006), dirigida por Claudia Llosa, como nueva ficción fundacional. Aborda el tratamiento simbólico de los personajes y su relación con los espacios como marca de una narrativa que supera las estructuras binarias de género que sustentan los romances fundacionales, así como las narrativas de tradición colonial. El artículo estudia cómo se subvierten las connotaciones que la geografía peruana tiene en términos de una asimétrica relación de poder: espacio andino y espacio costeño.

Palabras CLAve / espacio, movilidad, género, nueva ficción fundacional, Perú.
Abstract / The present work proposes a reading of the film Madeinusa (2006), directed by Claudia Llosa, as new foundational fiction. It analyzes the symbolic treatment of the characters and their relationship with space, as a crucial aspect of a narrative that surpasses the binary structures of gender that sustain the foundational romances, as well as other narratives of colonial tradition. The article studies how the connotation Peruvian geography has in terms of an asymmetric relation of power -Andean space and coastal space- is subverted.

KEYWORDS / space, mobility, new foundational fiction, gender, Peru. 

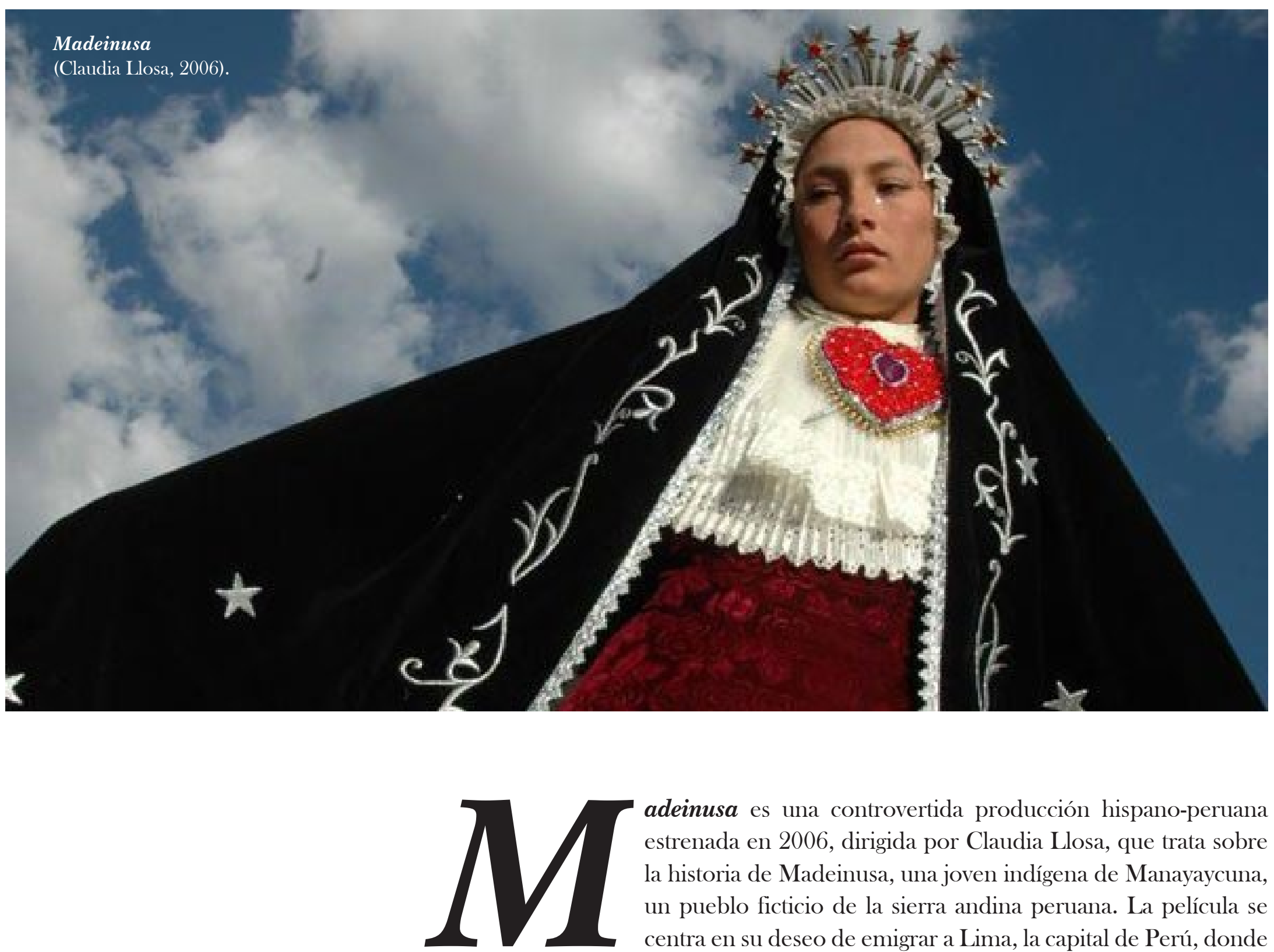

adeinusa es una controvertida producción hispano-peruana estrenada en 2006, dirigida por Claudia Llosa, que trata sobre la historia de Madeinusa, una joven indígena de Manayaycuna, un pueblo ficticio de la sierra andina peruana. La película se centra en su deseo de emigrar a Lima, la capital de Perú, donde supone que se encuentra su madre.

En Manayaycuna conmemoran una festividad llamada Tiempo Santo, una celebración religiosa que transcurre entre la muerte de Jesucristo y su resurrección. Durante este breve periodo de tiempo consideran que, al estar muerto Cristo, no existe el pecado a los ojos de Dios, con lo que todo acto es válido. Don Cayo, padre de Madeinusa y alcalde del pueblo, abusa de su hija y es asesinado por esta ya finalizada la celebración. Para evitar el castigo, Madeinusa acusa del crimen a Salvador, un joven ingeniero limeño recién llegado al pueblo. Finalmente, ella se marcha a la capital en el mismo vehículo en el que hubiera llegado Salvador, que muere víctima, presuntamente, de un linchamiento colectivo.

La película generó una tremenda controversia. La recepción de la obra ha dado lugar a consideraciones muy dispares, desde posiciones que la tildan de ser una producción deudora de la "tradición mediática de violencia cultural contra los pueblos indígenas 
de las Américas" (Pagán-Teitelbaum, 2008, p. 2), a otras que hablan de la película como una fábula feminista poscolonial: "My understanding of Madeinusa as an astute young woman who cleverly manipulates the passive role ascribed to her by native and criollo patriarchal societies differs fundamentally from the decidedly negative depiction of the character as abject, evil and perverted by Pagán-Teitelbaum, Zevallos and other critics" (Palaversich, 2013, p. 497). Zevallos-Aguilar (2006) la considera un ejemplo de feminismo neoliberal, un producto cultural que forma parte de los intentos de aniquilación de la cultura y población indígena: " $\mathrm{El}$ inconsciente político de Madeinusa se acopla a las propuestas de modernización neoliberal del Perú con un guiño feminista que se reconoce a primera vista” (p. 74).

La hipótesis de este trabajo es que Madeinusa puede leerse como la reelaboración de una nueva ficción fundacional. Los ejemplos clásicos de ficción fundacional en Latinoamérica están protagonizados por "star-crossed lovers who represent particulars regions, races, parties, economic interest, and the like" (Sommer, 1993, p. 5). Sommer establece el uso metafórico de los amantes como representantes de ciertas regiones, razas, intereses económicos, etc.; a la vez que califica a estos amantes como star-crossed. La expresión, heredada de Shakespeare, hace referencia al amor imposible, por circunstancias insalvables, de la pareja. Esto es representado en Madeinusa por el romance entre la indígena andina y el blanco limeño. Pero la voz crossed remite necesariamente al cruce, al intercambio, al dinamismo, y según propongo, al desbordamiento -más allá de sus límites- de un espacio geográfico. En Madeinusa nos encontramos con una representación dinámica de aquellos espacios que tradicionalmente actúan como mutuamente excluyentes en la tradición peruana: el espacio andino frente al espacio costeño, la dicotomía que sostiene el mito fundacional de la nación. Es decir, el proyecto nacional peruano, dividido en una retórica binaria espacial y de género, queda representado y superado en Madeinusa a través del tratamiento de unos espacios que quedan identificados con los amantes (susceptibles de desplazamiento) a través de una estrategia metonímica. Salvador y Madeinusa son representantes de una región, de una raza y, según la lógica del romance heterosexual, de un género. Como veremos, lo que aporta Madeinusa no es la mera identificación metafórica de los protagonistas del romance con los espacios dicotómicos, sino la posibilidad de leer esta identificación en términos metonímicos como un elemento móvil y dinámico que produce la desconstrucción de esta misma identificación.

Para Sommer, la metáfora del matrimonio en las antiguas ficciones fundacionales representa un momento de consolidación nacional. "The marriage metaphor slips into, or out of, a metonymy of national consolidation if we stop to consider how marriages bridged regional, economic, and party differences during the years of national consolidation" (p. 18). En Madeinusa nos encontramos algo distinto. En última instancia, la protagonista renuncia a acompañar a Salvador tras el encuentro sexual de ambos y decide abandonar por su cuenta el pueblo. Sus decisiones van encaminadas a lograr su propia autonomía: una autonomía del espacio andino, una autonomía de la raza indígena, una autonomía del género femenino. $\mathrm{Al}$ abandonar el espacio con el cual ha quedado identificada, la lógica de espacios dominantes y dependientes (masculinos y femeninos) queda rota, así como la caracterización tradicional que sustentaba la vieja ficción fundacional. El locus de enunciación de las prácticas de poder queda invertido (de Lima a la sierra) con la acusación final de Madeinusa (culpando a Salvador de la muerte de su padre), algo que permite su salida del pueblo. El espacio andino, representado por ella misma, abandona su propio emplazamiento con la migración a Lima.

Como señala Pérez Melgosa (2012), la película es una "pseudo-anthropological representation of the fictional Andean village of Manayaycuna” (p. 134). La cámara usa de la retórica del documental antropológico y parece posicionarse en una perspectiva que proyecta un mensaje inscrito en la tradición de travel writing que trabaja Pratt (1992). Esto es, la descripción ideológica de un espacio ajeno considerado 
atrasado desde el punto de vista de desarrollo civilizatorio. Siguiendo esta lógica, se documentarían las prácticas sexuales de Madeinusa. La naturaleza del esporádico acto copulativo, entre ella y Salvador, marca la imposibilidad de consolidar ese acto sexual dentro de la heteronormatividad familiar. Puede ser visto, pues, como un elemento de dominación sexual, racial y epistémica por parte del limeño. Este acto sexual sería una repetición de la retórica imperialista, una nueva visita a los espacios dicotómicos peruanos a modo de las decimonónicas ficciones fundacionales, "a romantic transformation of a particular form of colonial sexual explotation” (p. 95). En Madeinusa, la cámara no permite ver sino una resignificación de un espacio y una episteme, que por ser ajenas al ojo que mira (el de la directora) es reformulado en términos de dominación colonial y de dominación racial. Es decir, una perspectiva que da visibilidad a un objeto imaginario al que se le atribuye la naturaleza violenta y opresiva que el sujeto colonial dominador intenta sustraer de su propia identidad. Así se identifica al sujeto dominado y se permite la propia significación del sujeto dominador, como señalan las diversas lecturas que se han hecho sobre el pensamiento de Frantz Fanon. "Indeed, following Frantz Fanon, I suggest that the negative affects of the oppressors are 'deposited into the bones' of the oppressed” (Oliver, 2004, p. XIX). Este proceso de identificación tendría como objeto legitimar e inscribirse en una, según términos de Oliver, subject position de dominación política. El ojo camarográfico parece someter al objeto observado con una mirada imperialista que perpetúa el silencio de la subalternidad a través de la reformulación del estereotipo de la mujer indígena salvaje y sexualizada. "If, in the context of colonial production, the subaltern has no history and cannot speak, the subaltern as female is even more deeply in shadow" (Spivak, 1988, p. 28). Es un enfoque y una manera de mirar (y contar) desde ojos imperialistas.

En una primera lectura de Madeinusa parece dominar esta mirada que reitera el mito del indígena-salvaje. El mito del espacio andino donde, al estilo de las crónicas coloniales, el demonio engaña al ser humano y lo somete al pecado. La razón y la fe subyugadas a la violencia de las pulsiones biológico-animales. Este mensaje, como se ha apuntado, nace en el momento colonial y es reiterado constantemente dentro de la tradición peruana hasta el punto de producirse su institucionalización. Esto lo vemos en referentes muy cercanos a la directora, como Mario Vargas Llosa - a quien le liga una relación de parentesco-y su obra Lituma en los Andes (1993). La novela, creo, tiene cierta influencia en la producción de Madeinusa, aunque, según propongo, esta última permite una mirada más allá de la institucionalización de una visión negativa del espacio andino. Esto sucede a través de determinados elementos simbólicos que cristalizan en la reformulación de una nueva ficción fundacional y, lo que es quizás más importante todavía, en la muerte de la antigua.

La muerte es un elemento central en cualquier lectura que uno pueda hacer de Madeinusa, ya sea entendiéndola como una película que aporta algo nuevo, o como una película que perpetúa un mensaje colonial y patriarcal. Con su retórica documentalista nos muestra un espacio arcano, violentado por el atavismo andino donde lo mágico requiere del sacrificio. La película abre con el zumbido del chiririnka, el moscardón que en el espacio andino es premonitorio de la muerte. Poco después, la cámara nos remite a la protagonista cubriéndose las manos para hacer uso de un veneno, instrumento de muerte. En una primera instancia, este veneno es usado para acabar a las ratas que cercan el espacio doméstico, pero al final será usado para terminar con la vida de Cayo, el padre abusador. Si bien a través del veneno pareciera establecerse una conexión entre el padre y la rata, la conexión de esta primera escena de muerte es con Salvador, el joven ingeniero limeño que ha llegado para solucionar ciertos problemas en una cercana explotación minera. Esta conexión se da a través del elemento espacial. Esto es, Madeinusa coloca el veneno cercando la casa, creando un espacio donde las ratas no pueden entrar. Traspasarlo será su condena. Esto es análogo al significado del nombre del pueblo, Manayaycuna, que en quechua significa 


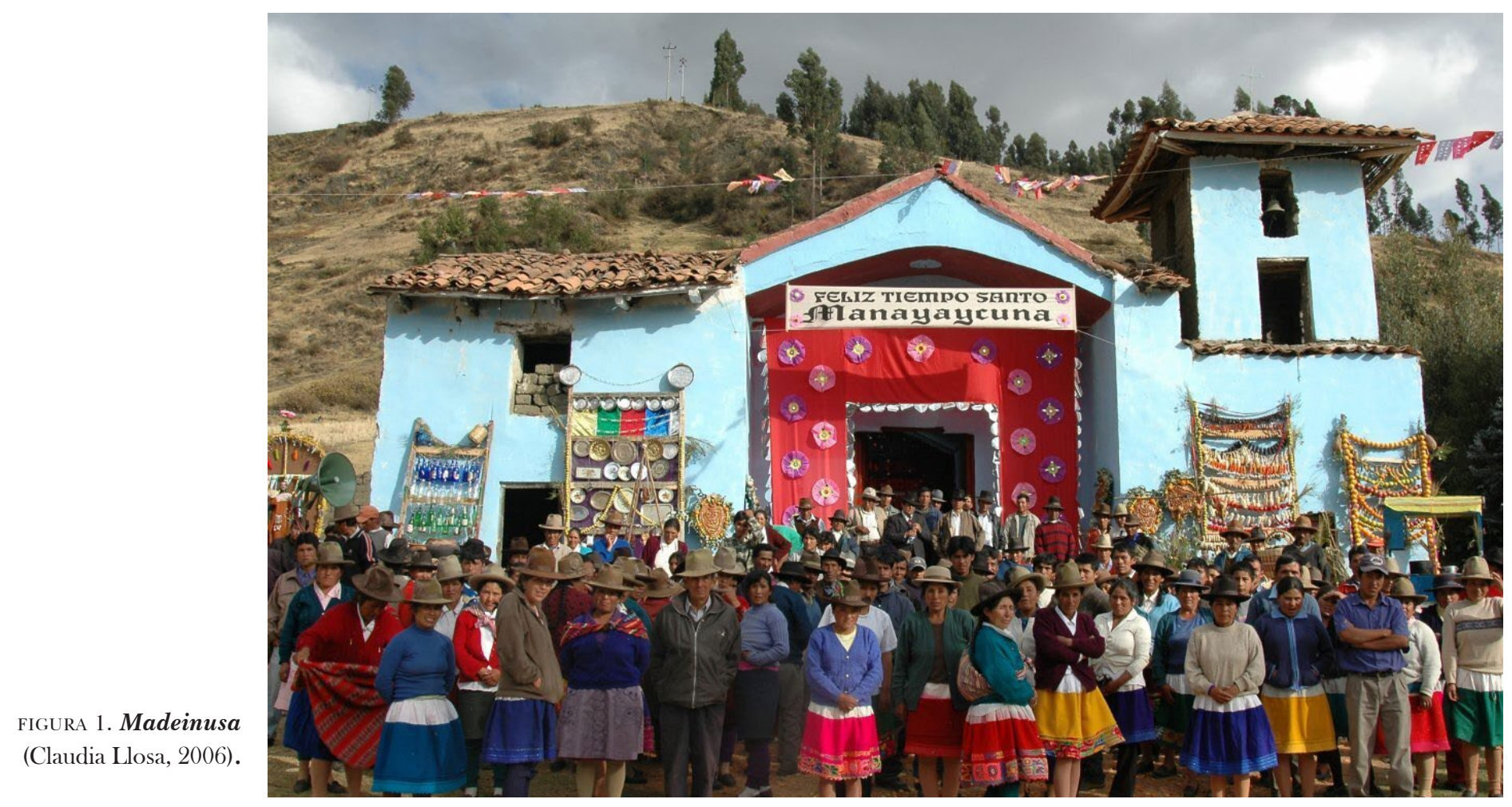

“donde no se puede entrar" [Figura 1]. La transgresión del mismo supone la caída de Salvador. La película abre con otra referencia a la muerte y a los espacios cerrados (el cementerio), cita enunciada desde el más allá. "Tú que pasas, mira y observa desgraciado lo que eres. Que este pueblo a todos por igual nos encierra. Mortal cualquiera que fueras, detente y lee. Medita que soy lo que tú serás y lo que eres, he sido”. En Tiempo Santo, sin embargo, se puede transgredir las leyes del espacio cerrado y la muerte, como se aprecia en la escena donde se produce la profanación de un ataúd en el cementerio, espacio cuyo elemento definitorio es el muro que lo cerca.

La muerte según Madeinusa trae buena suerte, ya que asegura que encontrar ratas muertas es la razón por la que los piojos no la atacan, al contrario que a su hermana, que sí está afectada por los mismos. Es decir, la muerte (que trae suerte) es la puerta para escapar y liberarse de este espacio social que le está sometiendo, que le está chupando la vida (como simboliza la metáfora de los piojos). Por su parte, Salvador, con su penetración en un espacio vedado, algo reforzado por su acto sexual con Madeinusa, entra en una senda narrativa que le conduce a una muerte segura. El espacio parásito es descrito a través de la melancolía que rodea a la materialidad de los objetos que Madeinusa atesora. Objetos que no pertenecen al mundo de subyugación patriarcal. Objetos foráneos a él. En primer lugar, vemos la intención de la joven de inscribirse simbólicamente en otro espacio al escribir superpuesto su nombre sobre un póster en el que se lee Maribel, una escena donde se manifiesta el deseo de la protagonista. La melancolía es sostenida por la música extradiegética, que queda continuamente asociada a la presencia de objetos que no pertenecen a este espacio, como las reliquias de Madeinusa y una fotografía que le entrega Salvador (y que Madeinusa cose a su falda). Más adelante, la música será asociada a los aretes que dejó su madre atrás al marcharse. La música se usa también para subrayar a Madeinusa doliente en un momento de castración simbólica que sufre por culpa de su hermana, ya que esta cercena su coleta. En esta escena existe un juego simbólico que invita a la posibilidad futura de la apropiación del falo por parte de la protagonista, como se verá más adelante. Una apropiación que permite a Madeinusa salir de la aldea. La última vez que se usa la música es al final de la cinta, en el camión de El Mudo (el conductor), donde Madeinusa luce los aretes, lleva la fotografía al cuello y recompone la coleta en su muñeca anulando así la agresión de su hermana. 
La figura de la hermana funciona como una extensión de la antigua ficción fundacional que ha de ser dejada atrás: "Me voy a ir a Lima. Y tú no”. Su hermana es un recordatorio de la performatividad no subvertida, es la que lleva el pelo suelto siendo condenada por ello a tener la cabeza llena de piojos, la que se niega a encontrar roedores muertos. Es la que, en otra escena, no tiene la llave para abrir la puerta que encierra a Madeinusa cuando esta que atrapada en un ático (junto al resto de obsequios-ofrendas a la Virgen). De nuevo se refuerza el simbolismo de los espacios cerrados y las posibilidades, o no, de una moderna ficción fundacional al romper con sus muros.

Los objetos que ha ido atesorando Madeinusa representan cómo la imposibilidad del subalterno de hablar va a ser transgredida. Cayo, que llama porquerías a las reliquias de Madeinusa, quema parte de los objetos. En este primer momento, la figura paterna es poseedora del falo y reduce a cenizas la autoafirmación simbólica de Madeinusa en el póster. La muerte del padre abusador viene a permitir la cercenación de este falo opresor que todo lo reduce a cenizas y que todo lo encierra bajo llave, ya sea a Salvador, a su hija, o las ofrendas del pueblo. Planteo que el sentido simbólico de las muertes de Cayo y Salvador no es necesariamente signo del indígena sometido a las pulsiones de la violencia, sino que remite a una violencia que muestra la posibilidad de superar las performatividades asociadas a los espacios dicotómicos peruanos. El héroe liberador limeño ya no tiene sentido. Esto es, Madeinusa no perpetúa el mito de la violencia andina, sino que participa de un circuito de trasgresión y de lo que Butler, en su lectura de Wittig y otros autores, denomina actos subversivos corpóreos. "The task for women, Wittig argues, is to assume the position of the authoritative, speaking subject - which is in some sense their ontological grounded 'right' - and to overthrow both the category of sex and the system of compulsory heterosexuality that is its origin" (Butler, 1999, p. 115).
El abandono del lugar es facilitado por la muerte del padre incestuoso (incesto del que Salvador es testigo, toda una escena de virilidad fallida y no-intervención) y por la muerte de Salvador (penetrador de la Virgen, ya que Salvador y Madeinusa mantienen relaciones sexuales caracterizada ella como la Virgen María). Madeinusa se marcha a Lima, teórico núcleo de civilización heredero del sistema de representación del sujeto colonial colonizador, es decir del dominio fálico. Esto representa el regreso al seno materno, a la Madre (que ella piensa le espera en Lima). La performatividad binaria de los espacios queda así superada.

Como he señalado anteriormente, en la escena de la muerte de la rata anticipamos la muerte de Salvador. Es por ello innecesario hacer presente el linchamiento de aquel que ha traspasado los límites del espacio sagrado. Aquí que se hace evidente la conexión con Lituma en los Andes de Mario Vargas Llosa. Esta novela se inspira en los sucesos de Uchuraccay, de 1983, donde fueron asesinados ocho periodistas. El autor formó parte de la comisión de investigación de dichos sucesos. No es solo el tropo del linchamiento o las conexiones temáticas, sino también la manera de mirar del novelista la que marca a la directora. Como señala Mayer (1992), el autor peruano hace un uso constante de la retórica y justificación antropológica. "Vargas Llosa becomes the writer, observer, and commentator of political reality" (p. 475), la misma técnica que usa el ojo camarográfico de la directora peruana.

Madeinusa reelabora el tropo del linchamiento asociado a la naturaleza indígena por la retórica heredera de las relaciones de dominación coloniales. Ahora, este juega un papel fundamental en mostrar lo innecesario del romance fundacional. Es la muerte de las ratas (asociadas a Salvador) lo que permite en última instancia a la protagonista marchar a una Lima, quizás también ficticia, donde encontrarse con su madre. Salvador vuelve a ser conectado por la secuencia de escenas con unas ratas, a las que ya hemos visto el futuro que les espera en Manayaycuna. Es decir, en la película podemos sentir la latencia del linchamiento, ya que este no se hace 
explícito, aunque el desarrollo de la película invita al espectador a completar la narrativa más allá de los créditos finales, haciéndole partícipe del proceso de construcción de la historia al dar muerte mentalmente al personaje de Salvador.

En lo referente a los espacios, partiendo de la tradición andina, el espacio sagrado queda identificado con Madeinusa (personaje femenino). Esto se produce a través de un proceso de metonimia con rasgos de transculturación. Esto es, el cerro sagrado, cerro donde en la tradición andina se halla el origen del Inca (el cerro como Madre, aunque también la tradición asocia su nacimiento con el lago Titicaca), es en realidad considerado como una huaca (objeto sagrado). Esta huaca andina es a su vez identificada con la Virgen María de la tradición católica. Uno de los eventos principales de la celebración que antecede la llegada del Tiempo Santo, eje temporal donde se sitúa la narrativa, es la elección de una de las jóvenes (se presume que virginales-sagradas-inmaculadas) como Virgen. Esta retórica metonímica es reforzada con el elemento de lo visual al ser el escenario donde se produce la elección un decorado que nos remite directamente a lo anteriormente referido: el decorado representa a la Virgen caracterizada como un cerro. Es decir, el espacio sagrado andino adquiere no ya una resignificación simbólica e híbrida (católico-andina), sino una corporeidad susceptible de movimiento: Madeinusa caracterizada como Virgen. Esto se hace explícito en una escena posterior donde este escenario se convierte en una puerta que atraviesa Madeinusa ya entronizada en su papel de Virgen. Es esta posibilidad de dinamismo, esta posibilidad de atravesar el umbral, lo que la película aporta de nuevo al viejo mito nacional. Este dinamismo impulsa la ambición de Madeinusa, que no es otra que la de abandonar la aldea, su patria, y marchar hacia Lima, donde espera encontrar a su madre.

Tanto la localidad ficticia Manayaycuna, el pueblo al que nadie puede entrar, como su representación corpórea (la Virgen), son penetradas por una masculinidad externa (Salvador-Lima) que en teoría no pertenece al espacio andino, pero que, con su injerencia, les está posibilitando salirse de sus propias limitaciones geográfico-simbólicas. Es gracias a este dinamismo que los espacios femeninos y masculinos subvierten los rasgos de su performatividad, esos elementos que sostienen los romances fundacionales. Es decir, se puede leer la película más allá de una dicotomía entre Lima y Andes, o entre figuras masculinas y femeninas, para poder entenderla como una nueva ficción fundacional. Ahora, la ficción criolla del proyecto indigenista bajo la dirección del burgués limeño, que propone por ejemplo Clorinda Matto de Turner en Aves sin nido (1889), o la visión del indígena como encarnación de la nación peruana de González de Prada en su Discurso en el Politeama (1888), han quedado superadas.

Madeinusa ya no necesita del romance (fallido o no) para salir de la aldea. Madeinusa permite una lectura donde lo femenino reniega de los rasgos performativos que se intentan imponer desde el romance. Ahora, desde el propio espacio andino, se permite impulsar movimiento a unos elementos que se integran en un circuito regido por el principio de incertidumbre donde no se puede precisar la localización geográfica debido al dinamismo y al movimiento de los mismos. Esta incertidumbre es liberadora, es subversiva, es fundacional, es una deconstrucción de la performatividad asociada a espacios y géneros. "The margins of the nation displace the center; the peoples of the periphery return to rewrite the history and fiction of the metropolis" (Bhabha, 1990, p. 6).

Madeinusa es capaz de reescribir su historia, de abrir por sí sola la puerta que le encierra después de que el circuito comercial de lo femenino quede roto con la negativa de Salvador a escoger una de las ofrendas encerradas (entre las cuales se encuentra ella) a ofrecimiento paterno. Esa fallida negociación de los dos varones sobre el cuerpo de Madeinusa da como resultado un discurso donde la protagonista no cumple el papel que debiera. "It is because women's bodies -through their use, consumption, and circulation- provide for the condition making social life and culture possible, although they remain an unknown 'infrastructure' of the elaboration of that social life and culture" (Irigaray, 1985, p. 171). El rechazo 
al romance por parte de Salvador, subraya el hecho de que Madeinusa ya no es un bien susceptible de ser comerciado.

Como simboliza la escena donde Madeinusa sale por sí sola del ático en que su padre la encierra, es importante atender al tratamiento de los espacios de transición o de paso. La película tiene lugar en las punas, como se encarga de situarnos Madeinusa con su canto bilingüe. La puna es un concepto que refiere a lo transicional, ya que es el espacio que antecede a la cumbre andina, es el umbral de las sagradas cumbres nevadas [FIGURA 2]. Los dos personajes que podemos identificar como los nodos de la tradicional dicotomía geográfica-simbólica peruana, Salvador y Madeinusa (que hubieran sido protagonistas del viejo romance fundacional fallido) son puntualmente encerrados. Lo que tienen en común estos encierros es la incapacidad de las puertas de guardar lo que encierran. El umbral se nos presenta, pues, como un espacio de posibilidades, de trasgresión. Lo fallido es el encierro, no en vano Salvador acaba entrando en "el pueblo donde no se puede entrar”, y a su vez Madeinusa acaba saliendo del "pueblo encerrado", otra traducción válida del nombre de Manayaycuna, ya que opera como sinónimo dentro de la lógica lingüística quechua.

La narrativa, como hemos visto, sucede en Tiempo Santo, un periodo que, al igual que el espacio, es en sí mismo transitorio. Dios ha muerto (a través de su identificación con el Hijo), permitiéndose ahora en la aldea todo tipo de pecado. La muerte del Hijo abre una temporalidad de tránsito que nos remite a los tres días que pasan hasta su resurrección de entre de los muertos tras la Pasión. Se abre una puerta en el tiempo que parece permitir la salida de Madeinusa de su aldea, como insiste el personaje en su plan de fuga con Salvador. Este tránsito es diferente al tránsito mariano. María, Madre por excelencia, no conoce la muerte en su ascensión corpórea a los Cielos. Se establece así una figura femenina en posición

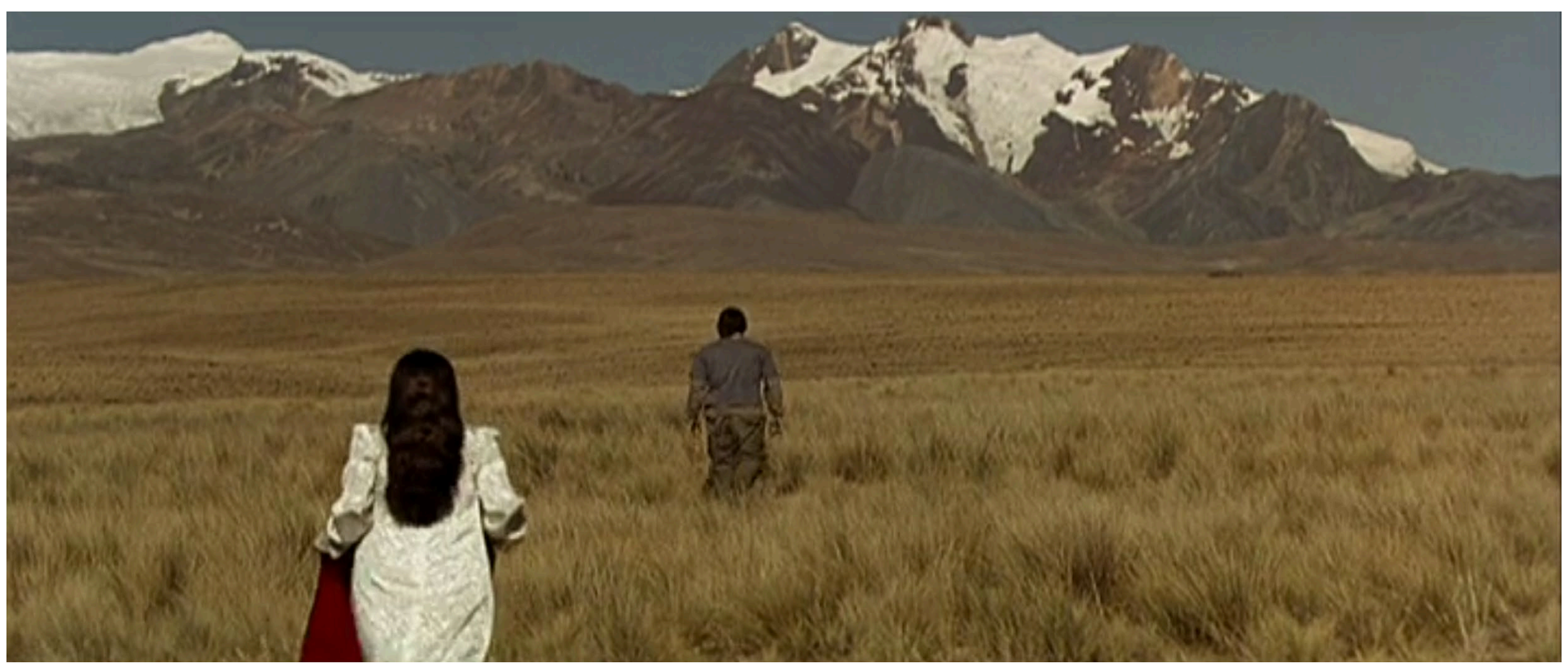


privilegiada. El desbordamiento de las performatividades asociadas a un género se produce en tanto que Madeinusa es identificada con la Virgen y no necesita de su muerte para proceder al tránsito, pero es a su vez también identificada con la pasión de Cristo en tanto que es el gran personaje sufriente de la película. Cristo es también identificado con el padre abusador a través de una toma donde Cayo queda reflejado en el espejo, evocando una anterior escena donde la estatua de Cristo es besada por la Virgen. Es decir, se construye un triángulo Cristo-Cayo-Madeinusa, y el falo del padre incestuoso es traspasado a Madeinusa a través del sufrimiento y el ejercicio de la violencia. Es por ello que se justifica la utilización retórica del pathos (palabra de la cual deriva la palabra pasión) para dar un giro en la transmisión del afecto. "The term 'affect' is one translation of the Latin affectus, which can be translated as 'passion' or 'emotion”" (Brennan, 2004, p. 3). La violencia que existe en torno a Madeinusa no es vista ya como locura y atavismo salvaje, sino como redención catártica que permite la posibilidad de futuro. El mártir sufriente es ahora mártir por ser el victimario. En otra escena de fuerte carga simbólica, las corbatas de los hombres son cortadas. Ahora las mujeres son las que integran a los hombres en un circuito de mercado sexual, abriendo la posibilidad de que sean ellas las portadoras del falo, abriendo la posibilidad de que ellas también puedan ejercer una violencia, en este caso, redentora.

En Tiempo Santo la narrativa del umbral y del espacio transitorio permite la formulación de un nuevo proyecto nacional donde el espacio andino puede desbordarse y marchar a Lima, y donde el espacio limeño puede penetrar a través de metonimia sexual en el pueblo al que nadie puede entrar. Se nos presenta el umbral como un espacio de posibilidades heterotópicas donde se yuxtaponen dos realidades aparentemente enfrentadas en las viejas ficciones fundacionales de la novela latinoamericana. "We are at the epoch of simultaneity: we are at the epoch of juxtaposition, the epoch of the near and the far, of the side-by-side, of the dispersed. We are at a moment, I believe, when our experience of the world is less that of a long life developing through time than that of a network that connects points and intersects with its own skein” (Foucault y Miskowiec, 1986, p. 22). Es en el cruce, en la intersección (o tránsito si entendemos este como el paso de un lugar a otro), donde se produce el nacimiento y la subversión. Uno de los momentos claves de la película, por su carga afectiva, es la llegada al pueblo de Salvador. Este se cruza con la Virgen (Madeinusa vestida de Virgen) y sus miradas se siguen la una a la otra. La sucesión de los planos del rostro de ambos personajes y el dinamismo de la cámara que acompaña, pero no detiene, el paso de los personajes, sintetiza el momento donde se produce el desbordamiento de los espacios más allá de sus limitaciones geográficas. La cámara acompaña después a Madeinusa en su carrera, dejando a Salvador fuera del enfoque. En relación con el movimiento, la carretera (un espacio cuya esencia es la de ser transitado) en Madeinusa juega un rol fundamental. Es el espacio que une los nodos costeño y andino, es el espacio que permite tanto la entrada en un pueblo "donde no se puede entrar", como la salida del mismo por parte de la identificación metonímica de este mismo espacio con el personaje femenino protagonista. La lógica de los espacios de transición, como las puertas y la carretera en Madeinusa, funciona como catalizadora de los elementos dinámicos que permiten romper con la representación de los espacios geográficos heteronormativos, abriendo así las posibilidades de una lectura alternativa.

La carretera no es transitada sin la presencia de un personaje aparentemente secundario, pero que es el facilitador y partícipe del proceso de integración de los dos ámbitos dicotómicos. El chofer del camión, llamado El Mudo, posibilita tanto la entrada como la salida de unos espacios donde la categorización de cerrado y estático ya no es operativa debido a su propio desbordamiento. Es decir, tanto Manayaycuna como Lima son espacios ficticios e intercambiables. El limeño, “¿qué estás hablando? yo no puedo volver a Lima”, no puede regresar a Lima porque Lima con su salida a través del viaje en el camión del Mudo ya no está como lugar-geográfico. Se ha producido 
una traslación del espacio simbólico, un acercamiento de la costa al espacio andino. El circuito se cerrará con la salida del propio espacio andino (Madeinsusa-Virgen-Cerro) de su espacio geográfico en ese mismo camión y por esa misma carretera. Esto es, los dos extremos son espacios ficticios que se mueven por espacios transicionales atravesando una serie de umbrales incapaces de retener los rasgos performativos que configuran la identidad que las retóricas del writing travel y la heteronormatividad colonial intentan imponer. En relación con la importancia de la muerte como elemento liberador (el establecimiento de la figura de Jesucristo como un elemento central de la película no es en vano, ya que la salida de Madeinusa es posible a partir de a la muerte de su padre y la integración de lo limeño en lo andino se realiza a través del linchamiento de Salvador), El Mudo funciona simbólicamente como el Caronte de la tradición clásica, no en el sentido de conductor de almas al inframundo, como pudiéramos leer si entendiésemos la película desde la mirada imperial, sino como integrador de dos espacios opuestos, como nexo y vínculo que posibilita la integración del proyecto nacional, de la nueva ficción fundacional.

Para reforzar el proyecto integrador de la nueva ficción fundacional, se atienden a los sistemas de representación epistémica tanto del sujeto colonial colonizador como del sujeto colonial colonizado. Se ha hecho mención a Mario Vargas Llosa, pero la película también remite directamente al universo simbólico andino de la obra de José María Arguedas. El chiririnka, anteriormente referido, ofrece al observador el zumbido premonitorio que sitúa al lector en una narrativa donde la muerte es el dinamizador de la trama. Es claro que la autora conoce los referentes arguedianos y hace uso de ellos. También vemos en la película el uso de la episteme indígena a través del elemento oralizante de la narración, elemento que subyace en parte a las producciones andinas como señala
Mazzotti en su trabajo sobre el Inca Garcilaso de la Vega, "que establecerá aquellos vínculos que la obra guarda con un discurso que excede largamente el universo escrito; discurso eminentemente oral que se hereda del conocimiento directo de la realidad andina” (Mazzotti, 1996, p. 19). Esta tradición, que Mazzotti asocia a la oralidad y a la coralidad (en tanto realidad polifónica del mestizaje), la vemos en Madeinusa a través de la canción bilingüe de la protagonista -que sitúa al espectador en la transitoriedad de los ejes temporal (Tiempo Santo) y espacial (las pumanas)-, así como en el coro de niñas que anuncian la apertura y el cierre de este tiempo de transición.

En la película, esta tradición se compagina con la tradición clásica donde el nombre de El Mudo, paradójicamente, representa la negación de esa oralidad anteriormente referida, así como la ruptura de la relación entre significante y significado dada la explicación del personaje sobre su nombre. El Mudo, en un giro catacrético, explica que es llamado mudo no por no hablar, sino por hablar mucho. Siguiendo con la posibilidad de que exista un sustrato clásico en cuanto a los referentes simbólicos de la directora, planteo la posibilidad de establecer un acercamiento entre Madeinusa y Psique, uno de los pocos personajes en salir del inframundo. Psique es a su vez la representación del último hálito que deja el cuerpo tras la defunción corpórea, la posibilidad de una nueva resurrección de entre los muertos, de una nueva ficción fundacional que deje atrás el cuerpo de la antigua. Madeinusa, el personaje femenino, funciona con su desbordamiento performativo y geográfico, con su movimiento a través de los espacios (y momentos) transicionales, como psicopompo (mariposa-ser que conduce a las ánimas al inframundo) de la antigua ficción fundacional. Es decir, Madeinusa representa la ruptura de la crisálida fálica del viejo romance fundacional latinoamericano. 


\section{Bibliografía}

Bнавна, H. K. (1990). Introduction: narrating the nation. En H. K. Bhabha (Ed.), Nation and Narration (pp. 1-8). Londres, Reino Unido: Routledge.

Butler, J. (1999). Gender Trouble. Feminism And The Subversion Of Identity. Nueva York, EE.UU.: Routledge.

Brennan, T. (2004). The Transmission of Affect. Ithaca, EE.UU.: Cornell University Press.

Foucault, M. y Miskowiec, J. (1986). Of Other Spaces. Diacritics, 16(1), 22-27. doi: https://doi.org/10.2307/464648

IrIGARAY, L. (1985). The Sex Which is Not One. Ithaca, EE.UU.: Cornell University Press.

Mayer, E. (1991). Peru in Deep Trouble: Mario Vargas Llosa's 'Inquest in the Andes' Reexamined. Cultural Anthropology, 6(4), 466-504. doi: https://doi.org/10.1525/can.1991.6.4.02a00030

Mazzotti, J. A. (1996). Coros mestizos del Inca Garcilaso. Resonancias Andinas. Ciudad de México, México: Fondo de Cultura Económica.

Oliver, K. (2004). The Colonization of Psychic Space: A Psychoanalytic Social Theory of Oppression. Minneapolis, EE.UU.: University Of Minnesota Press.

Pagán-Teitelbaum, I. (2008). El glamour en los Andes: la representación de la mujer indígena migrante en el cine peruano. Revista Chilena de Antropología Visual, (12), 1-30.

Palaversich, D. (2013). Cultural Dyslexia and the Politics of Cross-cultural Excursion in Claudia Llosa's Madeinusa. Bulletin of Hispanic Studies, 90(4), 489-503. doi: https://doi.org/10.3828/bhs.2013.31

Pérez Melgosa, A. (2012). Cinema And Inter-American Relations: Tracking Transnational Affect. Nueva York, EE.UU.: Routledge.

Pratt, M. L. (1992). Imperial Eyes: Travel Writing And Transculturation. Nueva York, EE.UU.: Routledge.

Sommer, D. (1993). Foundational Fictions: The National Romances Of Latin America. Berkeley, EE.UU.: University of California Press.

Sprvak, G. (1988). Can the Subaltern Speak? En C. Nelson y L. Grossberg (Eds.), Marxism and the Interpretation of Culture (pp. 271-313). Londres, Reino Unido: Macmillan.

Zevallos-Aguilar, J. (2006). Madeinusa y el cargamontón neoliberal. Wayra, (4), $71-81$ 


\section{Filmografía}

Llosa, C. (Directora \& Productora) \& Morales, J. M. y Chavarrías, A. (Productores). (2006). Madeinusa. Perú, España: Vela Films.

Ignacio D. Arellano-Torres (España) es estudiante de doctorado en la Universidad de Stony Brook. Entre sus intereses se encuentran los problemas del desplazamiento, la movilidad de los cuerpos y el espacio. Ha trabajado una diversidad de temas, culturas y periodos, que van desde la literatura del Siglo de Oro español al cine latinoamericano contemporáneo. Ha publicado artículos, o aceptados para publicación, en revistas como Hispania, Hispanófila, Romance Notes, Catedral Tomada, RILCE, La Perinola, Ínsula y Anales Cervantinos. 